\title{
A associação da dor cervical crônica e migrânea influência no desempenho do teste de resistência cervical?
}

\author{
Amanda Rodrigues' $^{1}$, Marcela Mendes Bragato' ${ }^{(\mathbb{D})}$, Lidiane Lima Florencio² ${ }^{(\mathbb{D})}$, Luisa Bigal ${ }^{3}$, \\ Marcelo Bigal $^{4} \mathbb{D}^{\mathrm{D}}$, Débora Bevilaqua-Grossi'
}

'Faculdade de Medicina de Ribeirão Preto, Universidade de São Paulo, São Paulo, Brasil.

¿Universidad Rey Juan Carlos, Madrid, Espanha.

3Universidade da Carolina do Norte, Chapel Hill Gillings School of Global Public Health, Carolina do Norte, Estados Unidos da América.

${ }^{4}$ Ventus Therapeutics, Research and Development, Waltham, Massachusetts, United States of America.

\author{
Introdução \\ O relato da dor cervical nos pacientes com migrânea pode contribuir negativamente para o aumento das crises de \\ cefaleia e severidade da alodínia cutânea, com impacto nas atividades de vida diária.
}

\section{Objetivo}

Verificar se o desempenho de mulheres com migrânea durante o teste de resistência muscular cervical é afetado pelo diagnóstico clínico de migrânea e/ou dor cervical, pelo relato de dor de cabeça e/ou pescoço ou ambos os componentes.

\section{Métodos}

100 mulheres estratificadas por diagnóstico (migrânea, dor cervical, ambas e nenhuma) e pela dor autorreferida (com ou sem cefaleia e/ou dor cervical) realizaram o teste de resistência muscular cervical. As participantes foram questionadas se tiveram dor no pescoço e /ou cabeça. Foi realizado teste T de Welch e o teste McNemar.

\section{Resultados}

Para o diagnóstico, os dados revelaram que durante o teste de resistência em flexão, os pacientes com migrânea e dor cervical apresentaram menor resistência quando comparados ao controle $(p<0,05)$. Durante a extensão, os grupos de dor cervical com ou sem migrânea tiveram tempo de sustentação menor que o grupo controle $(p<0,05)$. $\mathrm{Na}$ estratificação quanto ao relato de dor durante o teste em flexão e extensão, os dados mostraram que aqueles que relataram cefaleia, sustentaram por menos tempo do que aqueles sem cefaleia. Resultados semelhantes foram observados ao comparar aqueles com dor de cabeça e pescoço e sem dor durante o teste $(p<0,05)$.

\section{Conclusão}

O diagnóstico clínico não foi único fator decisivo para o desempenho da resistência muscular cervical. A presença do relato de cefaleia associada ou não à dor no pescoço após o teste também limitou a atividade. Portanto, há um componente de sensibilização central que proporciona a alteração no desempenho, porém ainda não é possível determinar se é o fator que atua diretamente no baixo desempenho de migranosas.

Palavras-chave: Migrânea, Dor cervical, Disfunção muscular, Resistência, Dor de cabeça. 